\title{
The Impact of Empowering Human Resources on Achieving Effective Performance: A Field Study on Workers in Jordanian Newspapers
}

\author{
Jasmien Jamal Abed AlRazaq \\ Master of Business Administration / Al-Balqa Applied University \\ jasmien_33220066@yahoo.com
}

\begin{abstract}
This study aimed to identify the impact of empowering human resources with its dimensions (efficiency at work, exchange and sharing of information, training and development, independence at work) in achieving effective performance among workers in Jordanian newspapers. The study sample was chosen randomly from the employees of the Jordanian newspapers (publications), and their number was (298) workers, and the questionnaire relied on in collecting data.

This study concluded that human resources empowerment was generally of high importance, while it was found that performance effectiveness was of medium importance.

The results of the simple regression test showed a statistically significant effect at the level $(\alpha \leq 0.05)$ to enable human resources to achieve the effectiveness of performance in the Jordanian newspapers.

The study recommended the need to raise the level of independence at work, work to raise the level of
\end{abstract} training and development among workers in Jordanian newspapers.

Keywords: human resources empowerment, performance effectiveness, Jordanian newspapers.

DOI: $10.7176 / \mathrm{JLPG} / 114-08$

Publication date:October $31^{\text {st }} 2021$

\section{Introduction to the study:}

The literature of the concept of empowerment, appeared in the nineties of the last century by (Sadan) by introducing the concept of empowerment in her book entitled (Empowerment and community planning) in the year 1997, in which she addressed that the roots of the concept of empowerment go back to three scholars who are considered the first to contribute to it (Barbara \& Solomo), where she emphasized that empowerment is a means of collective action for struggling Americans, then was followed by the two scholars (Peter Berger and Richard Newhouse) who proposed the concept of empowerment as a means to improve care through social institutions, but the greater role was played by the scientist (Julian Rapaport) in providing empowerment with its theoretical framework based on Marxist social theory to solve emerging problems, through relationships between individuals and provide a general approach to create an organizational environment capable of dealing with social situations in order to achieve effective performance, especially within organizations (Sadan, 2004).

Performance is the focus of attention in contemporary management. Performance, whether at the level of the individual or the group, is the way to determine the level of efficiency and effectiveness of the organization, and the performance of the individual affects, to one degree or another, the collective performance, and thus is reflected on the performance level of the organization (Brosoli, 2018).

It can be said that improving employee empowerment plays a role in raising performance rates in the organization, by releasing the potential of human resources from the accumulated experiences and expertise and participating in teamwork, which contributes to increasing trust between management and workers and thus achieving effective performance in organizations (Jawad, 2008).

The relationship of human resources empowerment with individual and collective performance is shown by promoting creative efforts and encouraging responsibility, and giving working individuals greater freedom to act, does not prevent the obstruction of routine procedures, but rather raises their self-confidence, increases their job satisfaction and loyalty, and affects their desires and needs. In survival and development in their work, as the compatibility of working individuals with empowerment methods works to raise the level of their creativity and achieve the goals of the organization through effective performance (Radi, 2010).

Study problem and questions:

The following sub-questions emerged from the main question:

Human resources are one of the most important foundations of success for operating organizations and on many of their sectors and sizes, also human resources are the most important productive resources at all. Organizations cannot work without people, and it has become very necessary to empower human resources by various means (efficiency in work, exchange and sharing of information, training, development and independence) because of their critical impact on the effectiveness of the performance of employees, and it is 
noted that many Institutions lack the empowerment of human resources, in light of the practice of some erroneous administrative patterns, which appeared in the publications sector, and related to Jordanian newspapers, which negatively affected the effectiveness of performance, as some articles were published in Jordanian newspapers recently, in addition to protest vigils about the closure of some Jordanian newspapers in addition to the desire to drop some of the boards of directors of Jordanian newspapers, for several reasons represented in the lack of development or modification of professional tools, and the websites were not exploited In advertisements and attracting advertised companies and institutions, in addition to the lack of proper leadership practice, poor efficiency at work, and failure to activate work teams (Al Jazeera Net - Amman, 2017).

Due to some erroneous practice and the lack of empowerment of employees working in Jordanian newspapers, in addition to the Corona virus crisis, which created a work environment that is not classified as good, due to the workers not being able to exercise their abilities and competencies, due to reducing the number of employees by certain percentages, in addition to the inability to mix, and the imposition of distance Due to the repercussions of the Corona crisis (Covid-19), this negatively affected the effectiveness of performance and productivity in general. Many scholars and researchers have studied this subject as one of the important and influential topics as a study (Omar and Qwaidari, 2020; Farwana study, 2020; Kariuki and Murimi, 2015; Chen, 2011).

The problem of the study was represented in the following main question: "What is the impact of human resources empowerment on Achieving effective performance in Jordanian newspapers. The following sub-questions emerged from the main question:

1. What is the level of human resources empowerment in its dimensions (efficiency at work, exchange and sharing of information, training and development, independence at work) in Jordanian newspapers?

2. What is the level of performance effectiveness in Jordanian newspapers?

3. Is there an impact of human resources empowerment with its dimensions (efficiency at work, exchange and sharing of information, training and development, independence at work) in achieving effective performance in Jordanian newspapers?

\section{The importance of the study}

The importance of the study is highlighted in its consideration of the impact of empowering human resources in achieving effective performance on Jordanian newspaper workers in both the theoretical and practical aspects.

Theoretical aspect: The theoretical importance of this study lies in its research on the issue of the impact of human resources empowerment on achieving effective performance on Jordanian newspaper workers, and its enrichment of theoretical literature by addressing the main variables adopted in this study, whether the independent variable or the dependent variable, because these variables are contemporary. And influential, in addition to being a knowledge addition to the Jordanian and Arabic library alike.

The practical aspect: The practical importance is embodied in discovering the weaknesses and strengths in the Jordanian newspapers when they apply the concept of empowering human resources, which plays a positive role in achieving effective performance, as well as providing suggestions and recommendations to the management of Jordanian newspapers and working on their implementation and benefiting from them in order to follow the best methods to achieve effective performance for working individuals., which is reflected on the quality and efficiency of the performance of Jordanian newspapers, as the press is one of the influential and vital sectors in contemporary societies, especially when it depends on an empowered human element capable of achieving and working efficiently and effectively.

\section{Objectives of the study}

- Identifying the level of human resources empowerment in its dimensions (efficiency at work, exchange and sharing of information, training and development, independence at work) in Jordanian newspapers.

- Identifying the level of performance effectiveness in Jordanian newspapers.

- Identifying the impact of human resources empowerment in its dimensions (efficiency at work, exchange and sharing of information, training and development, independence at work) in achieving effective performance in Jordanian newspapers.

\section{Study hypothesis:}

Ho.1: There is no statistically significant effect at the level of significance $(\alpha \leq 0.05)$ to enable human resources in its various dimensions (efficiency at work, exchange and sharing of information, training and development, independence at work) on the effectiveness of performance in Jordanian newspapers. 
Procedural definition of the study

Empowerment: granting individuals in Jordanian newspapers the authority and freedom to work, liberating them from official and direct censorship, and giving them the confidence to assume responsibility to carry out their work.

Efficiency at work: It is the implementation of work in the Jordanian newspapers in correct ways with the least effort and time and at the lowest possible cost of resources, and this variable is measured by paragraphs (5-8) in the questionnaire.

Exchange and sharing of information: It is the transfer and reception of information related to enabling Jordanian newspaper workers to work and take the necessary decisions and implement them. This variable is measured by paragraphs (21-24) in the questionnaire.

Training and development: They are activities and programs to continuously develop skills, capabilities and professional and scientific expertise and work to develop them to obtain the best outputs. This variable is measured by paragraphs (25-29) in the questionnaire.

Independence at work: It is doing work in Jordanian newspapers in the best ways and skills without the need to review the official, and take responsibility for the decisions that were taken, and this variable is measured by paragraphs (30-33) in the questionnaire.

Performance effectiveness: It is the ability to achieve the desired goals in the Jordanian newspapers in the right way, and it is measured by paragraphs (1-12) in the questionnaire.

Study limitations and limits

The limitations of the study consisted of the following points:

A. Spatial boundaries: The study was conducted on Jordanian newspapers (publications) in the capital, Amman.

B. Human limits: workers in Jordanian newspapers (publications).

C. Time limits: the academic year 2020/2021

\section{Empowering Human Resources:}

Empowerment has emerged as the most widely used concept in modern management, as it highlights its interest in human resources, and enhances the relationship between employees and their superiors by improving their skills by providing them with knowledge and experiences that qualify them to participate in decision-making and problem solving (Muwaffaq and Saudi, 2018), and giving them the authority in a way that enables them to Act freely and think what they see fit, without having any fears or obstacles that may reject their actions or be approved by their superiors, and this in turn enables qualified workers to save the organization in adversities that may be exposed to it, through the optimal use of their empowerment processes which It reflects their commitment and loyalty to the organization, thus creating distinct opportunities for survival and continuity (Movahedi and Azarpira, 2016).

Empowerment of human resources is a process through which the capabilities and culture of empowerment among the employees of the organization are enhanced, so the individual adapts his goals in proportion to the goals and orientations of the organization (Farajilahijan et. al., 2012, as it is known as a new policy that seeks to support and build the capabilities of employees and their participation in shaping The future vision and objectives of the organization, by meeting the desires and needs of individuals and linking their needs to the vision and objectives of the organization (Brown and Harvery, 2006), and to establish an effective and correct participatory administrative relationship, organizations need to reach distinct results, and to achieve this it is possible to focus on seven basic components issued by The word (Empower) is used by the organization with the aim of achieving participatory administrative work, and each letter in the word (Empower) expresses a concept, and the following is an explanation of those concepts (Stirr, 2003):

- E-Education: Every organization seeks to achieve positive results, and to achieve this, it must build, support, motivate and direct its employees in the right way, to reflect on their performance in the organization and to achieve the best results for the organization, through educational programs that work on refining skills and capabilities Personnel working in the organization.

- M-Motivation: Most individuals are afraid of change and it is difficult to accept it, as a small percentage of individuals accept adapting to new changes, and here comes the role of the organization in motivating workers and working to increase their motivation by adapting to new changes, and encouraging them to accept The concept of empowerment, through the use of a number of orientation programs.

- P-Purpose Objective: The main content of empowerment is the success of the performance of the employees to achieve the success of the organization, so the employees must understand and accept the vision, strategy and objectives of the organization.

- O-Ownership: Ownership represents the amount of knowledge and capabilities that employees in organizations possess that enable them to carry out their duties; Which benefits them either materially or 
morally, and it may be a unique and valuable experience for them, and motivate them by their superiors to participate and be able to make decisions.

- W- (Willingness to Change): the desire for change: the departments' desire to apply the process of empowerment to workers and to give them training programs and build their capacities, which will help organizations adopt new processes and practices for employees, to increase their ability to face change.

- E. (Ego Elimination): Getting rid of the ego: change for the organization and individuals is not an easy way at all, and most bosses do not prefer to participate and delegate part of their powers to others, and prefer to follow routine administrative patterns, but empowerment is an important mechanism in changing the pattern of work in the organization, and the way Effective to get rid of the old methods of management and works to remove the manifestations of arrogance among decision-makers, by adopting a new and effective methodological approach, which returns to the organization, bosses and employees with the best results.

- R. Respect: If the concept of respect is not one of the basic elements in the policy and philosophy of the organization, it will not reach and the empowerment will not be able to reach its goal and provide the best outputs.

Some considered empowerment as practices implemented by the organization's management to invest the ideas and capabilities of employees, through processes and programs such as training and motivation, and to increase the motivation of workers to employ their ideas at work and to involve them in the decision-making process in order to achieve the goals of the organization and work to improve its efficiency and effectiveness in the competitive environment in a manner consistent with the scope of the environment Technological and Cultural (Al-Asoufi, 2017).

A description of the concept of human resources empowerment as a mechanism, through which the individual worker participates with the following four inputs: information related to the performance of employees, decision-making regarding the goals, directions and performance of the organization, information that will allow workers to understand and contribute to the performance of the organization, and the benefits that employees will obtain from the organization. (Yüksel and Erkutlu, 2003).

\section{The Importance of Human Resources Empowerment:}

The importance of human resource empowerment is represented by several contributions, which can be summarized through the following two dimensions (Uzunbakak, 2015: Celik, et. al., 2014):

\section{The Importance at the individual level:}

- Empowering human resources helps give workers more appropriate responsibility to carry out the tasks assigned to them, develop their sense of accomplishing work at higher levels in their work, and make workers faster in making decisions.

- Empowerment of human resources contributes to increasing the efficiency of employees and achieving satisfaction for customers and customers and works to improve the level of quality in organizational processes, and helps to provide job satisfaction for employees and increase motivation and belonging to the organization.

- Empowering human resources leads to the development of the skills and capabilities of employees, as it is an opportunity to develop their knowledge and creative abilities in all areas and organizational levels.

\section{Organizational importance:}

- Empowering employees helps to increase the ability for organizational creativity and creation of innovations by unleashing the creative capabilities of employees, and this enhances the organization's ability to adapt to the changing business environment, especially in advanced technology organizations.

- Empowerment provides an infrastructure to influence the most important dimensions of organizations survival, namely organizational effectiveness, by achieving the organizational process with the least effort and cost, and exploiting all available resources and competitive advantage by achieving an advantage for the organization, especially the service industry, given the importance of the two dimensions in keeping pace with changes in the environment surrounding the organization.

- Empowering the human resource is one of the most invested mechanisms practiced by modern departments in organizations with the aim of maintaining their profits and increasing their productivity through achieving effectiveness by developing the services provided and satisfying and serving customers.

\section{Performance Efficacy}

The concept of performance effectiveness:

The concept of performance effectiveness lies in the ability to achieve the right things and actions, and to avoid doing unproductive things. It was stated in the scientific management that increasing production lies in achieving efficiency, and effective organizations are those that contain distinguished workers in their 
performance, and this earns the organization the characteristic of excellence that will compete with other organizations, and that attention to study the behavior of workers and knowledge of their needs, desires and aspirations and support them to achieve their goals, and make them the most important element In the organization and an integral part of it, it will motivate them to achieve the highest efficiency of their performance, and by giving confidence to the workers and giving them the freedom to act and choose in the course of work and those who represent them in the organization will achieve the highest levels of effectiveness for them, and give them greater motivation to do the work more effectively (Hazem, 2016) .

The concept of effective employee performance is an issue of great importance in organizations today, because of its high resonance in keeping pace with the competitive environment and working for the continuity and survival of the organization (Areiqat and Nji, 2016).

\section{Studies in Arabic:}

A study of (Omar and Qweidry, 2020) entitled: The role of training (empowerment) in achieving the effectiveness of the performance of employees - a field study at the Algeria Telecom Corporation in the municipality of Djelfa. This study aimed to identify the impact of empowerment in achieving the effectiveness of performance at Algeria Telecom in the municipality of Djelfa. With the aim of collecting and distributing data in the manner of a comprehensive survey, this study concluded a number of results, the most important of which is that there is an impact of empowerment in achieving the effectiveness of performance in the research institution. Employees inside or outside the organization, and increase the awareness of employees of the concept of empowerment and clarify its importance.

A study (Khaddam et. al., 2020) entitled: Human resource management strategies and their impact on smart organizations - modified role: empowering workers - a field study on a group of pharmacies operating in the capital Amman governorate. This study aimed to identify the impact of human resource management strategies in its dimensions (recruitment and appointment, training and development, performance evaluation, motivation) in smart organizations with the presence of the modified role to empower workers in a number of pharmacies operating in the Jordanian capital governorate. The study is for all employees at the administrative levels in pharmacies operating in the Jordanian capital governorate, whose number is (50) individuals, and the data was collected by distributing a questionnaire to the study sample of (42) individuals. Human resource management with its dimensions studied in smart organizations in the pharmacies surveyed, and there is an impact of the modified role to enable workers to modify the impact of human resource management strategies in its dimensions in smart organizations in the pharmacies surveyed, and this study recommended the need to conduct more similar studies on other study sectors.

A study (Al Douri, 2018) entitled: The effect of empowering employees on job performance in business organizations - a field study on a sample of employees at Zain Jordan Telecom. The purpose of this study is to identify the impact of employee empowerment in its dimensions (meaning of work, work efficiency, work independence, work development) on job performance in Zain Jordan Telecom Company. Zain Jordan Telecom in Jordan, and a questionnaire was developed with the aim of collecting data and distributing it to the study sample of (385) individuals. The surveyed company, and the absence of an impact on the dimension of work efficiency and after the development of work on job performance in the company under study, and this study recommended a number of recommendations, including the need to pay attention to developing and improving workers' awareness of the dimensions of empowerment investigated in general and after (work efficiency, and work development) in particular.

A study (Al-Mahal, 2017) entitled: "Training practices and their impact on empowering workers - an applied study on food manufacturing companies in the Yemeni industrial sector." This study sought to demonstrate the relationship of influence between training practices and the dimensions of employee empowerment. Of workers from different administrative levels in four Yemeni companies working in the field of food industries, the study summarized to a number of conclusions, including, there is a strong influence relationship between the variable of training practices and the dimensions of employee empowerment represented in (independence and freedom of action, possession of knowledge, sharing of information) and it was the strongest influence relationship in the dimension of independence and freedom of action, and this study recommended, the institution's support for all appropriate training programs to empower workers, and work to build the capabilities and skills of workers by the organization, by providing training programs that help workers on how to use and exchange information and give them a greater range of delegated powers of the chiefs.

A study (Dahou and Hacini, 2018) entitled: "Successful Employee Empowerment: Major Determinants in the Jordanian Context", the study examined the concept of empowering workers and the main factors affecting the implementation of the empowerment initiative represented by (job design, transformational leadership, decision-making authority, continuous training, development and information sharing, and self-managed work teams) in Jordanian commercial banks. The study population consisted of employees of Jordanian commercial banks, and a questionnaire was prepared with the aim of collecting data and distributing it to a simple random 
sample of (113) individuals. Empowering workers, exchanging information and job design has the strongest impact on empowering workers, and the study recommended the need to search for additional factors that have an impact on employee empowerment strategies.

A study (Hanaysh, 2016) entitled: "Examining the Effects of Employee Empowerment, Teamwork, and Employee Training on Organizational Commitment". This study aimed to measure the effects of three factors (employee empowerment, teamwork and employee training) on organizational commitment in Malaysian higher education institutions. The data was collected using an online survey of (242) individuals, and the results indicated that empowering workers has a significant positive impact on organizational commitment, and it was found that the impact of teamwork on organizational commitment has a positive impact, and this study reached several recommendations, the most important of which are The need to focus on employee empowerment, training, participation, and teamwork in the surveyed universities.

A study (Kariuki and Murimi, 2015) entitled: "Employee Empowerment and Organization Performance of Tata Chemicals Magadi Ltd, Kenya". This study sought to show the relationship between the dimensions of employee empowerment represented in (decision-making, independence, training and information exchange) and organizational performance using gender, age and tenure as a control variable. One of the most important results of the study: All models were positive, as gender had a significant contribution to organizational performance, in addition to training and information exchange which moderated the contribution of empowering workers, while the decision-making dimension was not of great importance in organizational performance.

\section{Study Methodology:}

"The study methodology is a set of steps and procedures that the researcher follows to explain a phenomenon, and it is also a set of approaches, suggestions, concepts and tools that combine among them, as it provides the researcher with a guide to follow to realize the various phenomena to verify the validity or incorrectness of a particular hypothesis or theory, (Obaibat, 2021). In conducting the study, the researcher relied on the quantitative descriptive approach, which is concerned with a set of methods that take care of data collection, organization, summarization and presentation in a clear manner, and the calculation of various statistical measures such as central tendency, skewness and kurtosis, and measuring the strength of the association (Al-Ashi and Boras, 2019).

\section{Sampling Unit:}

The sampling and analysis unit for this study consists of all employees of the Jordanian newspapers "publications", whose job titles are (director, assistant director, head of department, division head \& employee). The Jordan Times, Al-Anbat newspaper, and Table (1) show the demographic characteristics of the study sample members.

Table (1) Frequencies and Percentages of General Information of Respondents

\begin{tabular}{|c|c|c|c|}
\hline Variable & Categories & Repetition & Percentage \\
\hline \multirow{7}{*}{ Job title } & manager & 12 & $\% 4$ \\
\hline & Assistant manager & 5 & $\% 1.7$ \\
\hline & Department head & 37 & $\% 12.4$ \\
\hline & Division head & 13 & $\% 4.4$ \\
\hline & officer & 215 & $\% 72.1$ \\
\hline & other & 16 & $\% 5.4$ \\
\hline & Total & 298 & $\% 100$ \\
\hline \multirow{5}{*}{ age } & 30 years or less & 30 & $\% 10.1$ \\
\hline & $31-35$ years & 105 & $\% 35.2$ \\
\hline & $36-40$ years & 116 & $\% 38.9$ \\
\hline & 41 years and over & 47 & $\% 15.8$ \\
\hline & Total & 298 & $\% 100$ \\
\hline \multirow{6}{*}{$\begin{array}{l}\text { Educational } \\
\text { qualification }\end{array}$} & Diploma & 108 & $\% 36.2$ \\
\hline & bachelor & 164 & $\% 55$ \\
\hline & Master & 21 & $\% 7$ \\
\hline & $\mathrm{PhD}$ & - & - \\
\hline & other & 5 & $\% 1.7$ \\
\hline & Total & 298 & $\% 100$ \\
\hline \multirow{2}{*}{$\begin{array}{c}\text { Years of } \\
\text { Experience }\end{array}$} & 5 years or less & 31 & $\% 10.4$ \\
\hline & $6-10$ years & 186 & $\% 62.4$ \\
\hline
\end{tabular}




\begin{tabular}{|c|c|c|c|}
\hline Variable & Categories & Repetition & Percentage \\
\hline \multirow{4}{*}{} & $11-15$ years & 35 & $\% 11.7$ \\
\cline { 2 - 4 } & $16-20$ years & 28 & $\% 9.4$ \\
\cline { 2 - 4 } & 21 years and over & 18 & $\% 6$ \\
\cline { 2 - 4 } & Total & 298 & $\% 100$ \\
\hline
\end{tabular}

\section{Scale correction key}

It was taken into account that the scale (Likert quintuple) used in the study should be graded according to the rules and characteristics of the scales as follows:

\begin{tabular}{|c|c|c|c|c|}
\hline \multicolumn{5}{|c|}{ Answers alternatives } \\
\hline Strongly Agree & agree & neutral & Disagree & Strongly Disagree \\
\hline 5 & 4 & 3 & 2 & 1 \\
\hline
\end{tabular}

Based on the foregoing, the values of the Mean reached by the study were dealt with according to the following equation to reach the degree of judgment on the paragraph:

The highest value - the lowest value of the answer alternatives divided by the number of levels, ie:

$\underline{(5-1)}=\underline{4}=1.33$ and this value is equal to the length of the category.

$$
33
$$

So the low level of $1.00+1.33=2.33$

And the average level is from $2.34+1.33=3.67$

And the high level is from 3.68-5.00

The following is an explanation of the parts included in the questionnaire:

Part one: "Questions related to general information: (job title, age, educational qualification, number of years of experience)."

Second part: Paragraphs related to the measurement of the study axes. Table (2) shows the distribution of the scale items, which are as follows:

Table (2) Distribution of the study tool items that measure its axes

\begin{tabular}{|c|l|c|}
\hline Dimension & Statement & $\begin{array}{c}\text { No. of } \\
\text { Paragraphs }\end{array}$ \\
\hline 1$)$ & Efficiency at work & 4 \\
\hline 2$)$ & Exchange of information & 4 \\
\hline 3$)$ & training and development & 5 \\
\hline 4$)$ & independence & 4 \\
\hline 5$)$ & performance efficacy & 12 \\
\hline & Total paragraphs of the study tool & 29 \\
\hline
\end{tabular}

Validity and reliability of the study tool: Virtual validity: Apparent honesty is represented in examining the content of the questionnaire items and ensuring their quality. It is also called "the veracity of the arbitrators", as the degree of representation of the items of the questionnaire components is judged and judged by a group of experts and specialists. Accordingly, the study tool was presented to (academic arbitrators), and after their reading for the paragraphs of the questionnaire and its contents, some modifications and observations were indicated, after which the researcher made all the modifications and observations. Stability of the study instrument: The stability of the study tool indicates the stability of responses over time and is measured by (Cronbach Alpha) coefficient, and the result is statistically acceptable if it is greater than (0.70) (Sekaran and Bougie, 2020), and Table (3) shows that: 
Table (3) value of (Cronbach Alpha) internal consistency coefficient

\begin{tabular}{|l|c|c|}
\hline \multicolumn{1}{|c|}{ Dimension } & $\begin{array}{c}\text { (Cronbach Alpha) } \\
\text { Internal Consistency } \\
\text { Coefficient }\end{array}$ & $\begin{array}{c}\text { No. of } \\
\text { paragraphs }\end{array}$ \\
\hline Efficiency at work & 0.914 & 4 \\
\hline Information sharing & 0.910 & 4 \\
\hline training and development & 0.904 & 5 \\
\hline Work independency & 0.907 & 4 \\
\hline performance efficacy & 0.905 & 12 \\
\hline All paragraphs of the study tool & 0.857 & 29 \\
\hline
\end{tabular}

We note from Table (3) that the value of the internal consistency coefficient (Cronbach Alpha) for the study tool items ranged between (0.900-0.926), where the value of the total Cronbach Alpha coefficient was $(0.857)$, all of which are greater than $(70 \%)$ and this is a result of describing the study tool as stability. and can be relied upon for statistical analysis.

\section{Data analysis results and hypothesis testing}

Description of the Independent Variable Human Resource Empowerment:

This part of the study relates to the description of the human resources empowerment variable in order to determine the degree of relative importance of the study sample members, as the arithmetic mean and standard deviation of the responses of the study sample and the degree of approval of the dimensions of human resource empowerment shown in Table (4) were relied upon.

Table (4)

Mean, standard deviations, and the degree of importance for the dimensions of human resource empowerment

\begin{tabular}{|l|c|c|c|c|}
\hline Dimensions of HR Empowerment & Mean & $\begin{array}{c}\text { standard } \\
\text { deviation }\end{array}$ & Level & Rank \\
\hline Efficiency at work & 3.95 & 0.607 & High & 1 \\
\hline Sharing and sharing information & 3.67 & 0.747 & Medium & 2 \\
\hline training and development & 3.67 & 0.789 & Medium & 2 \\
\hline Independence at work & 3.58 & 0.780 & Medium & 4 \\
\hline general indicator & 3.71 & 0.529 & High & \\
\hline
\end{tabular}

It is evident from Table (4) that the empowerment of human resources achieved a general arithmetic mean of (3.71) and a standard deviation (0.529), which is of the high level, and in the first place came the efficiency at work with an arithmetic mean (3.95) and a standard deviation (0.607), which is of the high level. And in the second place, the exchange and sharing of information, and training and development came with an arithmetic mean (3.67) and two standard deviations (0.747 and 0.789), which are from the average level, and in the fourth place came independence at work with mean $=(3.58)$ and a standard deviation $(0.780)$, which is from the medium level.

\section{-Description of the dependent variable on the effectiveness of performance:}

Table (5) shows the arithmetic mean, standard deviation, and rank of the respondents' answers towards the variable (performance effectiveness), which was measured based on (12) items.

Table (5)

The arithmetic mean and standard deviation of the respondents' answers towards the performance effectiveness variable

\begin{tabular}{|c|r|c|c|c|c|}
\hline No. & Paragraph & Mean & $\begin{array}{c}\text { Standard } \\
\text { deviation }\end{array}$ & Level & Rank \\
\hline 42 & $\begin{array}{r}\text { The organization's management is keen on } \\
\text { the effectiveness of communications } \\
\text { between employees. }\end{array}$ & 3.59 & 0.982 & Medium & 1 \\
\hline 38 & $\begin{array}{r}\text { The organization's management is keen to } \\
\text { constantly improve its output. }\end{array}$ & 3.56 & 0.942 & Medium & 2 \\
\hline 39 & $\begin{array}{r}\text { The organization is distinguished by } \\
\text { providing its products upon request. }\end{array}$ & 3.54 & 0.988 & Medium & 3 \\
\hline 43 & $\begin{array}{r}\text { Management is keen to support the } \\
\text { completion of work without errors. }\end{array}$ & 3.54 & 0.985 & Medium & 3 \\
\hline
\end{tabular}




\begin{tabular}{|c|c|c|c|c|c|}
\hline No. & Paragraph & Mean & $\begin{array}{l}\text { Standard } \\
\text { deviation }\end{array}$ & Level & Rank \\
\hline 40 & $\begin{array}{r}\text { The organization focuses on constantly } \\
\text { satisfying its customers. }\end{array}$ & 3.51 & 0.904 & Medium & 4 \\
\hline 44 & $\begin{array}{l}\text { The skills of employees are compatible with } \\
\text { their job duties in the organization. }\end{array}$ & 3.51 & 0.904 & Medium & 4 \\
\hline 45 & $\begin{array}{r}\text { The organization's management is keen to } \\
\text { constantly increase the number of its } \\
\text { customers. }\end{array}$ & 3.51 & 0.892 & Medium & 4 \\
\hline 41 & $\begin{array}{l}\text { The organization's management is keen to } \\
\text { provide a safe work environment. }\end{array}$ & 3.49 & 0.885 & Medium & 8 \\
\hline 36 & $\begin{array}{l}\text { The organization's management is keen to } \\
\text { provide its products at the lowest costs. }\end{array}$ & 3.42 & 0.972 & Medium & 9 \\
\hline 34 & $\begin{array}{r}\text { The employees of the organization perform } \\
\text { their work as planned. }\end{array}$ & 3.36 & 0.954 & Medium & 10 \\
\hline 37 & $\begin{array}{r}\text { The organization's management is keen to } \\
\text { provide its products in accordance with the } \\
\text { needs of customers. }\end{array}$ & 3.36 & 0.965 & Medium & 10 \\
\hline \multirow[t]{2}{*}{35} & $\begin{array}{r}\text { The organization's management is keen to } \\
\text { constantly achieve its goals. }\end{array}$ & 3.28 & 0.995 & Medium & 12 \\
\hline & Total & 3.47 & 0.774 & Medium & \\
\hline
\end{tabular}

Table (5) indicates that the trends of the study sample towards the variable (performance effectiveness) were of a medium level, as the arithmetic mean of the total score was (3.47) and with a standard deviation (0.774), where the Mean ranged between (3.59 - 3.28), as the paragraph ( 42), which states that "the organization's management is keen on the effectiveness of communications between employees" ranked first with an arithmetic mean (3.59) and a standard deviation (0.982) and a medium degree, while paragraph (35) achieved the last rank, which states that "the organization's management is keen to achieve its goals constantly with an arithmetic mean (3.28), a standard deviation (0.995), and a medium degree.

Study hypothesis test results:

This part of the study aims to test the main hypothesis, which states the following:

Ho.1: There is no statistically significant effect at the level $(\alpha \leq 0.05)$ to enable human resources in its various dimensions (efficiency at work, exchange and sharing of information, training and development, independence at work) on the effectiveness of performance in Jordanian newspapers.

To test the first main hypothesis, a stepwise multiple regression test was used in order to identify the impact of human resource empowerment in its various dimensions (work efficiency, information exchange and sharing, training and development, independence at work) on the effectiveness of performance in Jordanian newspapers, and Table (6) explains it.

Table (6)

Multiple regression analysis to identify the impact of human resource empowerment in its various dimensions (efficiency at work, exchange and sharing of information, training and development, independence at work) on the effectiveness of performance in Jordanian newspapers.

\begin{tabular}{|r|c|c|c|c|c|}
\hline \multicolumn{1}{|c|}{ Dimensions } & B & $\begin{array}{c}\text { Standard } \\
\text { error }\end{array}$ & Beta & T value & Sig. \\
\hline Efficiency at work & .124 & .059 & .098 & 2.103 & $* .036$ \\
\hline Sharing and sharing information & .122 & .052 & .119 & 2.346 & $* .020$ \\
\hline training and development & .335 & .050 & .344 & 6.699 & $* .000$ \\
\hline Independence at work & .462 & .045 & .469 & 10.278 & $* .000$ \\
\hline
\end{tabular}

* Statistically significant at the level $(0.05 \geq \alpha)$ tabular value $(\mathrm{t})=( \pm 1.96)$

It is clear from Table (6), and by following up on the values of the (t) test, that the sub-variables related to the empowerment of human resources in its dimensions (efficiency at work, exchange and sharing of information, training and development, and independence at work) have an impact on the effectiveness of performance in Jordanian newspapers. (t) calculated $(2.103,2.346,6.699,10.278)$, respectively, which are significant values at the level of significance $(\alpha \geq 0.05)$. 


\section{Conclusions:}

In light of the results of the statistical analysis of the answers of the study sample members, the researcher reached a set of results, which are as follows:

The results of the study showed an increase in the level of relative importance of the dimensions of human resources empowerment in Jordanian newspapers, as it achieved an arithmetic mean (3.71) from the viewpoint of the study sample members, and the dimension of efficiency came in the first order, and after the exchange and sharing of information it achieved the second place, and it came in the rank Third, after training and development, and in the last place, after independence at work.

On the other hand, with regard to the level of the dependent variable related to (performance effectiveness) in the Jordanian newspapers, it was found that the performance effectiveness came at an average level from the point of view of the study sample members.

It has been proven that there is a statistically significant effect at the level $(\alpha \leq 0.05)$ to enable human resources with its combined dimensions, respectively (efficiency at work, exchange and sharing of information, training and development, independence at work) on achieving effective performance of Jordanian newspapers.

\section{Recommendations:}

The findings of this study, recommends the following:

- Raising the level of independence at work, by focusing on the independence of workers in their work, and encouraging the management of the operating organization to self-motivate, because this benefits the effectiveness of performance.

- Working to raise the level of training, and to involve employees working in Jordanian newspapers in many training courses; In order to develop their skills and abilities, to run the work well, which is reflected in the effectiveness of performance.

- Focusing on the exchange and sharing of information, and working on facilitating the organization's communication systems, to facilitate the transfer and sharing of information between the employees themselves and the employees and departments of the Jordanian newspapers.

- The necessity of urging the administrative leaders to clarify the objectives and strategies for the working individuals to improve performance levels.

- Raising the level of performance effectiveness of Jordanian newspapers, by improving performance outputs and increasing productivity in Jordanian newspapers.

\section{References}

- Al Jazeera Media Network, (2017), Jordan's newspapers are dying and 400 websites on their behalf, visit November 3, 2020, electronic version: https://Aljazeera.net/news/reportsandinterviews/2017/1/9.

- Al-Asoufi, B. B., (2017). The Impact of Employee Empowerment on the Success of Organizational Change: A Study in Privatized Enterprises in Jordan. Journal of Public Administration and Governance. 7(1), 87-101.

- Al-Douri, Zakaria, (2018), the impact of empowering workers on job performance in business organizations - a field study on a sample of employees of Zain Jordan Communications Company, the Scientific Journal of Seyhan University, Volume (2), Issue (1), p. 82-91.

- Al-Mahal, Tariq, (2017), Training Practices and Their Impact on Empowering Workers, Journal of Economic Sciences, Vol. (18), No. (2), p. 75-92.

- Areiqat, A. Y., and Naji, B., (2016). The Role of Employee's Empowerment Strategy in Improving Organization's Effectiveness. Dirasat: Administrative Sciences. 43(2), 907-922.

- Barsouli, Fawzia, (2018), The Impact of Empowerment on Human Performance - A Field Study in the Directorate of Civil Protection in the Wilayat of Batna, an unpublished Ph.D. thesis, University of Mohamed Khider - Biskra, Algeria.

- Brown, D. R., and Harvery, D., (2006), An External Approach to Organizational Development. Prentice Hall. USA. 
- Celik, A., Iraz, R., Cakıci, A., and Celik, N., (2014). The Effects of Employee Empowerment Applications on Organizational Creativity and Innovativeness in Enterpriseses: The Case of Oiz. European Scientific Journal. 10 (10), 99-107.

- Dahou, K., and Hacini, I., (2018). Successful employee empowerment: Major determinants in the Jordanian context. Eurasian Journal of Business and Economics. 11(21), 49-68.

- Farajilahijani, P., Nojedehi, P., and Haghanipour, A., (2012). Human resources empowerment strategies in development projects. International Journal of Engineering Research and Applications. 2(3), 2760-2761.

- Jawad Mohsen Radi, (2010), Administrative Empowerment and its Relationship to Employee Creativity, AlQadisiyah Journal of Administrative and Economic Sciences, Al-Qadisiyah University, No. (1), p. 64, Kuwait.

- Khaddam, Amina and Artima, Hani and Badr, Basima, (2020), Human Resource Management Strategies and Their Impact on Smart Organizations, Modified Role: Empowering Workers (A field study on a group of pharmacies operating in the capital Amman governorate), the International Journal of Business and Economics, Volume (8), issue (1), p. 117-148.

- Movahedi, B., and Azarpira, M., (2016). Investigating the relationship between employees' empowerment and organizational commitment with organizational health mediation in Tehran Municipality, Revenue Recognition and Collection department. International Journal of Human Capital in Urban Management. $1(3), 221-236$.

- Omar, Amal and Guidry, Yamina, (2020), The Role of Training in Achieving Effective Performance of Workers, Unpublished Master's Thesis, Ziane Achour University of Djelfa, Algeria.

- Radi, Jawad, (2010), Administrative Empowerment and its Relationship to Employee Creativity, A Field Study on a Sample of Employees of the College of Administration and Economics, Al-Qadisiyah Journal of Administrative and Economic Sciences, Volume 10, Issue 1, pp. 62-84.

- Sadan, E., (1997). Empowerment and community practice.. Retrieved November 4, 2020, from : http://www.mpow.org.

- Sekaran, U., and Bougie, R., (2020). Research Methods for Business: A Skill Building Approach. (8th) Edition. John Wiley and Sons Inc. USA.

- Stirr, T., (2003). Fundamentals of Empowerment: Available At: https://www.tomstirr.com/NEW_Fundamentals_of_Empowerment_finalrev.pdf

- Uzunbacak, H., (2015). The Impacts of Employee Empowerment on Innovation: A Survey on Isparta and Burdur Organized Industrial Zones. The Journal of International Social Research, 8 (7), 977-989.

• Yüksel ,Ö., Erkutlu, H. (2003). Personeli Güçlendirme, G.Ü.İ.İ.B.F. Dergisi,1/2003, 131-142. 